\title{
Migration and Retention of Registered Nurses - A Case Study of Freetown
}

\author{
Umar N Jibril ${ }^{1}$, Umar Aliyu ${ }^{2}$, Amina G. Umar ${ }^{3}$, and Strasser, King Nadett ${ }^{4}$ \\ Mulikat A. Ibraheem 5 \\ ${ }^{l}$ Department of Nursing Science, College of Medical Sciences, University of Maiduguri, Nigeria. \\ ${ }^{2}$ National Hospital Abuja, Federal Capital Territory \\ 3 College of Education Technical Lafiagi, Kwara State, Nigeria \\ 4 Fourah Bay College Hospital, Fourah Bay College, MT. Aureol, Freetown, Sierra Leone. \\ ${ }^{5}$ University of Ilorin, Faculty of clinical Sciences, College of Health Sciences, Ilorin, Nigeria
}

\begin{abstract}
This study was conducted based on the health needs and deplorable health situation in West Africa sub region with particular reference to Sierra Leone. A quantitative study with descriptive design approach was used to observe and describe aspect of retention situation of Registered Nurses (RNs) in selected health institutions in Freetown. The main objective of the study was to describe the profile of the migration of nurses and to provide explanations for the observed retention problem of RNs in the health sector of Sierra Leone and specifically identify factors associated with the movement of registered nurses from Sierra Leone to other countries. The research sample was practicing RNs drawn from three Government Hospitals and three Private Hospitals. Questionnaires were administered to 155 practicing $R N s$ to elicit information on various factors responsible for mass migration. 133 questionnaires were retrieved, given a response rate of $94.4 \%$. The findings of the study showed that about $40 \%$ of RNs leave the country for jobs overseas, because of poor remuneration, poor working environment, delayed promotion and lack of incentives. Majority of respondents in both health institutions recommended better remuneration and recruitment of fresh graduate RNs into government workforce as remedies to retention and emigration problem in the country.
\end{abstract}

Keywords: Migration, Registered Nurses, Retention, Turnover, Volunteer

\section{Introduction}

There is a growing concern globally on the current flow of nurses migration, particularly from lowincome countries to middle and high-income countries. Recruitment practices of many countries such as the ones found in Africa sub region are thought to be worsening as number of nurses produced could not be properly managed, hence, these explained a stiff competition for pull of registered nurses (RNs) from the less developed countries to developed countries where they are better paid. In United State of America the current nursing shortage is expected to increase with an estimated shortage of 260,000 registered nurses by the year 2025 (Rother, \& Lavizzo-Mourey, 2009). This will lead to demand pull of RNs from developing to developed countries, currently, there are not registered nurses to fill open nursing positions in most health institutions of developed countries, and the ageing nurse population is in the increase which constitutes a great concern. The National Sample Survey of Registered Nurses, 2011 of America, report complement the growing trends in aging of Nurses that RNs over the age of 50 years comprised $44.7 \%$ of the nurse workforce in 2008 compared to $33 \%$ in 2000. These ageing nurses bring experience that new registered nurses lack. More experienced nurses' will begin to retire within the next 5-10 years creating concern that a lack of graduating nurses will enter the work force as replacements.

Retaining RNs has become a serious problem in Africa sub region due to the demand pull of RNs by the developed countries. The fact that the African health systems are historically poorly developed, the current trend of nurse shortages in the region has made health care services in some countries in a state of crisis. This situation according to Mujanja, Kibuko and Dovlo (2005) are responsible for double burden experienced by these countries, and already weak health systems tend to exacerbate the rate of migration leading to a surge in vacancy rates. The problem of retention of Registered Nurses (RNs) was also observed by Adeleye (2006) as a worldwide problem that affects most countries and Sierra Leone is no exception. Fadi El-Jardali, Nuhad Dumit, Diana Jamal and Gladys Mouro, 2007, found in their study that nurse migration in middle east especially Lebanon is a product of poor management and lack of effective retention strategies and sufficient knowledge about the context, needs and challenges facing nurses. Nurse migration in Lebanon underscores the importance of developing a monitoring system that would identify implications and help implement innovative retention strategies. Nurse migration out of Lebanon is likely to persist and even increase if underlying factors are not properly resolved. 
The International Council of Nurses (ICN,2003) reports that the nurse population ratio varies in different countries from less than 10 Nurses per 100,000 populations in most developing countries to more than 1000 Nurses per 100,000 in some developed countries a variation of more than one hundred fold. The average Nurse- Population ratio in high income countries is almost eight times higher than in low income countries while many countries, particularly in Africa, who are still struggling to provide a minimum level of Nurse staffing. Recent estimates in sub-Saharan African countries show a shortfall of more than 600,000 Nurses (ICN, 2003). This shortfall of RNs revealed the drastic gap created between the number of RNs in service and number needed to serve the growing population and this could be responsible for high infant and maternal mortality rates in developing countries due to lack of quality care. The crude death rate for 2006 in Sierra Leone was $17 / 1000$ which is considered high and the Infant mortality rate is estimated at 170/1000 and maternal mortality estimated at 1800/100,000 Ministry of Health and Sanitation (MOH\&S,2006). According to Zurn, Dolea, \& Stilwell (2005) "motivation at work is believed to be a key factor in the performance of individuals and organisations and is also a significant predictor of intention to quit the workplace." Mathauer and Imhoff (2006) emphasize: "Low motivation has a negative impact on the performance of individual health workers, facilities and the health system as a whole. Moreover, it adds to the push factors for migration of health workers, both from rural areas to the cities and out of the country. It is therefore an important goal of human resources management in the health sector to strengthen the motivation of health workers". Zurn, Dolea, and Stilwell (2005) stress that policy-makers and managers must strive to recruit people to the workplace and encourage them to stay in their posts and perform to an acceptable standard. It is within this context that policy-makers, planners and managers have turned their attention to using incentive systems to improve the recruitment, motivation and retention of health care personnel.

It is evidence that nurses' work environments contributed to negative patient outcomes as a result of organizational management practices, workforce deployment, work design and organizational culture, (Institute of Medicine, 2004). A similar report found that nurse staffing and managerial support were crucial to improving the quality of patient care, nurse dissatisfaction and nurse burnout. Research findings indicated that job and workplace characteristics played a key role in nurse satisfaction, (Hall, Doran, \& Pink’s, 2008).

A number of factors have been identified to motivate nurses by various studies in the developing countries which made the RNs to migrate from their country to other country mainly the developed countries. Some African countries, despite their countries domestic health care needs, cannot create enough jobs for the health professionals they train, thus motivating them to emigrate. Groff and Terhaar, (2010) Identified various causes of job stress and dissatisfaction which includes patient acuity, work schedules, poor physician /nurse interactions, new technology, staff shortages, unpredictable work flow or work load, and the perception that the care provided is unsafe. However, poor wages, economic instability, poorly funded health care systems, and safety concerns are other factors that make nurses leave developing countries to developed countries (Groff \& Terhaar, 2010). other factors such as inadequate management of health services, poor working environment, inadequate training or continuing educational training for higher qualifications are significant problems of job dissatisfaction and poor retention of nurses' in developing countries especially west Africa sub region with Sierra Leone inclusive, (Awases, Nyoni, Gbary, and Chatora, 2003). The retention problem of RNs in developing countries especially in African sub region which lead to mass movement of nurses to other countries is not just a problem for nursing, but they are health system problems which undermine health systems effectiveness and thus require health system solutions, with effective and sustained interventions.

Although, some RNs may wish to remain in their work places, but unbearable work environment made them change their decision. Letvak and Buck, 2008),reported in their study on the intention of RNs to remain in hospital based nursing shows a positive intent $(60 \%)$ while, some nurses were not sure of their intent to stay (25\% and $15 \%)$ as they were planning on leaving. Significant variables included: age, years worked in nursing, quality of care provided, and job satisfaction. The most frequent reasons reported for leaving the nursing profession was job stress $(28.4 \%)$ and retirement (16.3\%). Nurse turnover creates negative issues at the unit and organizational levels including, poor patient outcomes, increased safety concerns, financial strains, and increased poor nurse morale Jane a. Edwards, (2011) Also summarized in her research project (unpublished). Understanding why nurses leave nursing as a career or change employers is the key to nurse retention. Identifying environmental factors that may affect nurse retention allows healthcare employers an opportunity to implement changes that may increase job satisfaction and nurse retention.

Migration and retention situation in Sierra Leone is precarious as it loses quite a number of RNs resulting into lack of supervision in the hospital wards, lack of quality nursing care, absenteeism, and fatigue on the few existing nursing staff. The migration of nursing personnel out of the country has left most hospitals and clinics under staffed. Some wards in the newly refurbished teaching hospital (Connaught Hospital) could not go into full operation due to lack of nursing personnel to man these wards and units. Sierra Leone with about 5.5million people, (SL.Nat Pop. Census, 2006) has 202 registered nurses currently in the government employment (MOH\&S, 2006); compare with 364 RNs trained within the period of six (6) years, the estimate 
shows that quite a number of RNs were not employed and this consequently results in migrate internationally for greener pasture.

The country has only one institution that is, the Faculty of Nursing Sciences, University of Sierra Leone train registered nurses to serve about 5 million population and this college produces about $40-50$ registered nurses annually. Of recent, Njala University has commenced the training of RNs to complement those trained by University of Sierra Leone. The RNs who were in most cases not employed by the government (5-10\%) migrate internationally. Out of the 50-60\% nurses employed by the government yearly, about $30 \%$ leave government service (after midwifery training) either for a Private Health Sector/Non Governmental Organisation in the country or migrate internationally. (MOHS, 2006), this revealed the turnover rate of nurses which started in the late 1970 s to 80 s and worsened in the early 1990s due to the ten year civil war in Sierra Leone. The war exacerbate the problem of retention and turnover rate in the country. The few RNs who are employed were heavily concentrated in the capital city of Freetown to the detriment of larger population who leave in the provinces. Some chiefdom in the country could not even boast of one RN in their health facilities.

Several solutions had been suggested by various organizations and individuals to improve the retention situation and reduce migration of RNs out of the country. To foster staff retention, organizations need to develop positive work environments in which nurses' work. Among other things, nurses want safe workplaces that promote quality health care. "It is the role of the nurse executives and nurse managers to establish a work environment that supports professional practice, Cohen, Stuenkel and Nguyen, 2009, opined that Managers can empower nurses by providing opportunities to be in workgroup, committees and projects that are pertinent to the practice environment. An ideal work environment embraces teamwork, promotes shared governance minimizes stressors, fosters group cohesion and autonomy, aims for manageable workloads, and encourages supervisor support. Another ways that hospitals can motivate the RNs to increase satisfaction are employment incentives, benefits as incentives are related to job satisfaction, perceived stress, and intent to stay in the current job. The incentive system must be seen as desirable by the staff in order to impact retention (Wieck, Dols, \& Northam, 2009). Lee Ann Runy,2001; It's also important that nurses play an active role in shaping their environment. "Nurses want to work in a place that brings high quality care to patients and know they have a role in the process. Similarly in Sierra Leone to remedy the migration situation in the country's health system, the newly qualified nurses are retain in various government hospitals as volunteers (volunteer nurses) for possible employment in the future as the government cannot employ all qualified nurses probably due to insufficient fund, this measure ameliorate the acute shortage of RNs in some wards and units of the Hospitals.

Base on the above problem, the researchers aimed at investigate into the observed migration and retention problem of RNs in the health sector of Sierra Leone and specifically to assess the turnover rate of Registered Nurses, identify factors associated with the migration of Registered Nurses from Sierra Leone to other countries and examine how retention of RNs can be improved in the country.

Significantly, this study would be useful to Government for policy formulation in solving the retention problem, to Private hospitals to set standards and regulations on quality care, conducive workplace and adequate staffing, and to all health personnel, to improve their working environment.

\section{Materials and Methods}

\section{Study Setting}

Freetown is the capital city of Sierra Leone (SL) situated in the Western Area Province. It has a population of about 1.2 million people (SL.National Population Census, 2005). The population density is high along the coast and lower in the mountainous areas. There are two seasons, the rainy season and dry season. Due to its high population density, the study covered three selected governments' hospitals: the Connaught Hospital, Princess Children's Maternity Hospital and Children's Hospital, and three private hospitals: the United Methodist Church Hospital (Kissy), Choithram' Memorial Hospital (Hill Station) and Marie Stopes Hospital (Aberdeen) all in Freetown.

\section{Design}

A descriptive cross sectional survey design was used to observe and describe aspect of Migration and Retention of Registered Nurses in Freetown/Sierra Leone. There are two hundred and two (202) RNs working in Government service nationwide, (MOH\&S, 2006). One hundred and twenty five (125) RNs were sampled from the government hospitals and a total of thirty (30) RNs from three private hospitals constituting a total of 155 samples for the study.

\section{Sampling Process}

A two-staged stratified random sampling technique was used in selecting the sample from hospitals and various work units to ensure proportional representation. The government health facility constituted one stratum 
whilst the second stratum was from the private health facilities. In the case of the first stratum 125 RNs were targeted $(80.6 \%)$ while $30(19.2 \%)$ RNs were sampled from the private health facilities. Respondents were selected through the simple random sampling technique from lists provided by the Matrons in charge of the health facilities visited.

Out of 155 questionnaires distributed, 133 were retrieved, 103 Respondents (77.4\%) from the Government service and 30 Respondents (22.6\%) from the Private health institutions that is, (Non Governmental Organization, Mission or Private) which did not constitute part of the study sample. This gives a total response rate of $94.4 \%$. A pilot study was conducted in one private and one government hospital using 35 respondents which gave room for the improvement on the instrument used.

\section{Instrument}

A structured questionnaire was the main instrument for data collection, the questions items that are used for collection of primary data were made up of open-ended questions and fixed choice questions. The questionnaire comprises of three sections: Section A.seek information about Clinical Practice, section B. Information concerning Conditions of Service, Section C. Turn over rate of RNs in Sierra Leone, and section D. suggestions on how to minimize the migration of RNs and improve retention problem among RNs.

\section{Data collection procedure}

A total of 155 questionnaires were distributed to RNs in both Government 125 and Private 30. Out of 155 questionnaires administered, all questionnaires were retrieved from Private health facilities, while, 103 were retrieved from Government given a total of 133, with a response rate of 94.4\%. Secondary data on the training and employment of RNs were collected from records department of the Ministry of Health and Sanitation, Office of the Registrar Nurses Board of Sierra Leone and WHO statistical information service. The applications for conduct of research were submitted to the MOH\&S, WHO head office, the Registrar Nurses Board of Sierra Leone and the Private Hospitals for Consent. All respondents at government and private health institutions permission were sought to participate in the study.

\section{Data Analysis}

Some questions were pre-coded on the instrument prior to data collection; notes were transcribed from the secondary data and some open ended questions which were later coded after the data collection exercise. Data was computerized using Excel Spreadsheet and part of the analysis was done in excel. This data analysis was then presented into frequencies using descriptive statistics; that is, age was cross tabulated with type of employers and graphs were plotted to determine the relationship between the two variables.

\section{Results}

Records on turnover rates of Registered Nurses from the Ministry of Health and Sanitation and the Office of the Registrar for Nurses when compared with the number of RNs on employment indicates a glaring problem of migration and poor retention of RNs in the country.

\section{Turnover Rates of Registered Nurses in Sierra Leone}

Table 1 show that 364 of RNs graduated from the Faculty of Nursing Sciences, University of Sierra Leone between1998-2006. Only 202 RNs were employed into Government health facilities nationwide (MOH\&S 2006) which indicates that 162 RNs were partly employed by private health institutions or self employed. Data on RNs employed from 1998 to 2006 were not available at the MOH\&S due to ten years of civil war. There was a decline in turnover rate of RNs from 623 in 1993 to 266 in 2006, the war lead to migration of many RNs out of the country to other countries for jobs.

The finding (Table 2) shows a cross tabulation between two employers (private) and (government) of RNs that $6.0 \%$ and $7.0 \%$ of both Private and Non-Governmental Organization were first employed by government. This indicates that Government employed the bulk $(87.0 \%)$ of RNs. Although, the Private sector employs few of the RNs, it was observed that some private facilities have only one or two of the RNs in their institutions.

\section{Reasons why RNs leave to work abroad}

The study revealed that out of the total number of respondents in the two employer's institution, $32.0 \%$ of RNs in Private sector and 29.0\% RNs in Government opines that between 61.0 to $81.0 \%$ of RNs left the country for jobs abroad respectively.

Figure 2 attributed reasons of the RNs leaving country to poor salary, poor working environment and delayed promotion, $64.0 \%$ and $48.0 \%$ claimed that lack of housing facilities as well as lack of in-service training are responsible for the migration and poor retention of RNs in the country while, few percentages of the 
respondents opines that victimization on the part of management also contributed to their migration. On the suggestion on the improvement of retention condition of the RNs in the country, quite a large proportion of RNs are of the opinion that employers of any type should improve on their salary and allowance, better working environment and early recruitment of qualified RNs in to the services of government (fig.3).

\section{Discussion}

The findings of the study provided an insight into the deplorable condition of service and decayed infrastructures in the country health institutions which make the work environment unconducive, and this contributed to poor retention and mass emigration of RNs from Sierra Leone to other countries. The turnover rate among registered nurses was in the high side principally due to poor salaries and remuneration and poor working environments. The failures on the part of the government to provide conducive working environment contributed to low motivation of RNs to remain on their jobs. Low motivation and poor working environment affect nurses' performance in rendering quality care to clients. The findings corroborate result of a study by Zurn, Dolea, \& Stilwell (2005) which identified three factors as a key role in nursing performance, that is, the known ability of staff to do their job meaning that their knowledge, skills and experience to perform the job is dependent on the capacity or "can do" factors. The motivation of staff to put in effort to do the job (the ability or "will do" factors) are based on the organizational support or availability of resources and the presence of policies and practices conducive to performance, physical and social environment as these are necessary ingredients for positive work environment for RNs. Majority of the RNs in Government services were not satisfied with inadequate remuneration, poor working environment and lack of other motivational factors like housing and training facilities, these are factors responsible for migration and low retention of RNs in the country, this finding is also in agreement with findings of Fadi El-Jardali, Nuhad Dumit, Diana Jamal and Gladys Mouro (2007).

The findings of survey undertaken in five African countries by Awases, Nyoni, Gbary, and Chatora (2003) and Groff and Terhaar, (2010), agree with the results of this study, that factors such as inadequate pay or poor remuneration, poor management of health services, poor working environment, such as lack of equipment, inadequate training or lack of continuing education training nor qualifications are significant problems of job dissatisfaction and poor retention of nurses' in developing countries especially West Africa sub region.

\section{Training and Recruitment of RNs in Sierra Leone}

The training of RNs in Sierra Leone does not correspond with the growing population of the country to be served. The total number of 364 RNs were produced in 8 years (1998 -2006) and 202 RNs remain in government service, this implies that Sierra Leone looses about 162 RNs to other countries within the period under review, this explains the precarious situation of turnover rate of RNs in Sierra Leone. The Sierra Leone can boast of only two institutions that train RNs one located in the capital city, Freetown, and in the recent time the Njala University situated in Bo the second largest city in the country has started producing RNs. This is an indication that few nurses are trained in the country compared to health needs of growing population of 5.5million (Census, 2005). On the problem of retention of RNs, the Government retains the bulk of Registered Nurses $(87.0 \%)$ compared to a small number of RNs recruited by the Private health sectors (13.0 percent), these bulk of RNs were poorly remunerated. This lead to poor retention when more than 40.0 percent RNs leave for employment overseas, this was supported by MOH\&S (2006) record.

The researchers observed that some private health facilities have only one or two RNs or none at all in their institutions, indicating that the turnover rates of RNs are more in Government health service. This finding corroborate with what Mujanja et al (2005) observed that, in Africa, especially, sub-Saharan region, retention of nurses is a major problem in the health workforce in countries like Zambia, Sierra Leone, South Africa and Ghana, and availability of nurses in terms of ratio per population is very low in these countries. This according to Mujanja et al (2005) may be attributed to low production of nurses from training institutions, restrictions imposed on the production of Enrollment of nurses in the nursing training institutions.

\section{Reasons for RNs Migration Out of Sierra Leone}

The findings of the study reveals that lack of motivation and poor working environment are the main reasons why the country looses her RNs to other countries. Delayed promotion and late recruitment of RNs into the government service poses a problem of retention most especially the RNs who work as volunteers. This findings support the opinion of Awases, Nyoni, Gbary,\& Chatora (2003) and Groff \& Terhaar, (2010). The result also shows that majority of respondents were dissatisfied especially the RNs who work as casual employees for about 1-2 years even more after graduation before they are recruited into the civil service. In such situation RNs leave the job as soon as they have other jobs elsewhere because they work without salary or allowances. Less than two percent (1.4\%) gave various reasons such as lack of other jobs at the moment, poor shift hour arrangement and lack of supervision from senior staff as contributing factors to migration and 
retention problems. The reasons given above agrees with Buchan (2001) and Fadi El-Jardali, Nuhad Dumit, Diana Jamal , Gladys Mouro, 2007 respectively and RNs whose opinions were that retention of workers on the job is based on individual motivation and contacts and that in recent times there is a strong demand pull for registered nurses in the developed world and this pull with better remuneration and conducive working environment motivate the RNs from less developed countries to seek employment abroad. About (98.6\%) of respondents interviewed opines that those who remain on the jobs claimed they will leave the country if the opportunity arises. Family commitment was also cited by RNs in government service as reasons for remaining in the country. This can be compared with the Connelly, Bott, Hoffart and Taunton (1997) study on retention of nurses in which they found that characteristics of the organization in terms of promotional opportunity and recruitment poses a problem of retention of staff and characteristics of the nurses themselves in which they cited family reasons for retaining the job on the other hand.

\section{Improvement of Retention Situation as Opined by the Respondents}

To minimize emigration of RNs and improve the retention of RNs, there should be better remuneration which includes increase salary and allowances, favourable work environment and better management of staff and facilities. These findings were in line with the Sierra Leone Nurses Association (SLNA) position paper to the government during the sensitisation campaign and meetings, advocating for better remuneration, better working environment and better management of staff and health facilities (SLNA, 2006: unpublished report).

The opinion of the respondents on the measures to minimize migration and improve retention of RNs, irrespective of the type of employer, majority of respondents opines that better remuneration (better salary, better allowances), better working environment, and early recruitment into the civil service and others such as continuing education and honesty in the part of both Government and Private employers are needed to improve the working conditions of nurses in the country. The RNs opinion was in agreement with Zurn, Dolea, \& Stilwell (2005) who stress that policy-makers and managers must strive to recruit people to the workplace and encourage them to stay in their posts and perform to an acceptable standard. Cohen, Stuenkel and Nguyen, (2009), were of the opinion that Managers can empower nurses by providing opportunities to be in workgroup while, Wieck, Dols, \& Northam, (2009) and Lee Ann Runy (2001); opine that the incentive system must be seen as desirable by the staff in order to impact retention and it's also important that nurses play an active role in shaping their environment, as Nurses want to work in a place that brings high quality care to patients and know they have a role in the process.

\section{Summary and conclusion}

Based on the finding of the study, it is pertinent to note that the factors associated with the migration of RNs from Sierra Leone, the causes of the movement of RNs and the solution to the problems of retention are congruent with the findings of various studies reviewed. These are inadequacy of nurses in the health work force especially RNs which plays a key role in nursing performance in the delivery of quality healthcare.

In conclusion, there is an increased level of migration of RNs from both government and private health facilities to abroad as a result of unfavourable work environment. Majority (97.5\%) of RNs leave because of inadequate remuneration and poor working environment which is a serious set back to the health care delivery to the growing population. Most of the respondents especially volunteers in government were disgruntled and dissatisfied with the work environment and opined that if the condition is not arrested it will lead to mass exodus of RNs from the country. The situation now calls for both government and private administrators in health sector to take a bold step in solving these problems to avoid a disaster in the health sector. Those in government institutions or ministries charged with the responsibility of resource allocation to health sectors must ensure appropriate and judicious use of funds for manpower development and improvement of work environment. This will enable Registered Nurses to stay and render the necessary care to clients. More studies need to be done to determine the relationship between the poor retention of RNs and the quality of care given to clients in both Government and Private health facilities in the country.

Based on the conclusion of the study, the researchers recommend to the government, health policy makers and other stake holders in health care delivery services, in sierra Leone, that:

- Each region of the country should have at least one School of Nursing to encourage rural recruitment of Registered Nurses from these regions.

- There should be promotional opportunities and adequate provision medical equipment, supplies and logistics, good light facility and adequate water supply for efficiency in job satisfaction.

- Remuneration must be adequate with a substantial increase in salaries and allowances; this will make the nursing profession more competitive with other professions and it will encourage the Nurses to stay and serve the people at home. 
- Government should link up with Non-Governmental Organizations and donor agencies to help improve remuneration of staff and working conditions of all health personnel.

- There should improvement in the absorption of Nurses into the health work force and fast track appointment made after training.

- To enhance skills and performance carefully planned skill based Nursing Updates are needed which must be in the form of on the job training that does not disrupt delivery of services.

- Hospitals should be equipped with internet facilities which can help on-line learning so that Nurses can improve and update their knowledge and skills for improved productivity.

- Monetary incentives need to be implemented for Nurses working as Volunteers

- Government should employ RNs working as volunteers as permanent employees in the civil Service and abolish casual working in the system.

- Nurses should be rotated regularly so as to improve their experience in both rural and urban settings and to reduce the possibility of migrating.

- Nurses Association and Board of Nursing and Midwifery of Sierra Leone must be involved in policy matters related to health issues, planning and decision making.

\section{References}

[1]. Adeleye, S.A. (2006). Nursing Personnel Shortage and its Effect on Health Care Delivery. West African Journal of Nursing, 17 (2): 174- 176.

[2]. Aiken, L.H., Sochaski, T. and Anderson, F. (1996). Downsizing the Hospital Workforce, Health Affairs, 15, 88-92.

[3]. Anonymous Nursing Extenders now found in 97\% of Hospitals, American Journal of Nursing News, (1991), 88-92.

[4]. Awases, M., Nyoni, J., Gbary, A., and Chatora, R.S. (2003). Migration of health Professionals in six countries: a synthesis report. World Health Organization, WHO Regional Office for Africa, Division of Health Systems and Services Development, Geneva, Switzerland.

[5]. British Broadcasting Corporation. (2006). Migration of Health Personnel in Africa, BBC World News. Bush house, London.

[6]. Buchan, J. (2001). Nurse Migration and International Recruitment, Nursing Inquiry, 8(4):203-204.

[7]. Buchan, J. and Sochalski, J. (Year?), Nurse Migration: Trends and the Policy Context. Bulletin of the World Health Organization (forthcoming).

[8]. Cohen, J., Stuenkel, D., \& Nguyen, Q. (2009). Providing a healthy work environment for nurses: The influence on retention. Journal of Nursing Care Quality,24(4), 308-315.

[9]. Fadi El-Jardali, Nuhad Dumit, Diana Jamal, Gladys Mouro (2007) Migration of Lebanese nurses: A questionnaire survey and secondary data analysis. accessed online at www.sciencedirect.com, on $23^{\text {rd }}$ feb. 2012. International Journal of Nursing Studies 45 (2008) 1490-1500

[10]. Frederick Hertzber, Bernard Mausner and Babara Snyderman, (1959), The Motivation to Work. New York: John Whaley and son. Inco.

[11]. Groff Paris, L., \& Terhaar, M. (2010). Using Maslow's pyramid and the National Database of Nursing Quality Indicators to attain a healthier work environment. The Online Journal of Issues in Nursing, 16(1), 1-8.

[12]. Hall, L. M., Doran, D., \& Pink, L. (2008). Outcomes of interventions to improve hospital nursing work environments. The Journal of Nursing Administration,38(1), 40-46.

[13]. International Council of Nurses, (2003), International Perspectives, International Nursing Review (INR). 52, 4-11.

[14]. Jane a. Edwards, (2011). Work environmental factors affecting staff nurse retention; A reseach paper submitted to the graduate school in partial fulfillment of the requirements for the degree masters of science. (unpublished)

[15]. Lee Ann Runy. (2001). Nurse Retention an Executive's Guide to Keeping one of your Hospital's most Valuable Resources

[16]. Letvak, S., \& Buck, R. (2008). Factors influencing work productivity and intent to stay in nursing. Nursing Economics 26(3), 159164. Microsoft@ Encarta® 2008. (C) 1993-2007 Microsoft Corporation. All rights reserved.

[17]. Ministry of Health and Sanitation, Sierra Leone. (2006). Primary Health Care Handbook, Freetown, Sierra Leone.

[18]. Mujanja, O. K., Kibuko, S. and Dovlo, D. (2005). The nursing workforce in sub-Saharan Africa, International Council of Nurses, Geneva, Switzerland, 17.

[19]. Rother, J., \& Lavizzo-Mourey, R. (2009). Addressing the nursing workforce: A critical element for health reform. Health Affairs, 28(4), 620-624.

[20]. Sierra Leone National Population Census Commission. (2005). National Population Census Report. Republic of Sierra Leone.

[21]. Sierra Leone Nurses Association. (2006). Report Submitted to the Ministry of Sanitation, unpublished.

[22]. Wieck, K. L., Dols, J., \& Northam, S. (2009). What nurses want: The nurse incentives project. Nursing Economics, 27(3), 169-179.

[23]. Zurn, P. Dolea, C. \& Stilwell, B (2005), Nurse Retention and Recruitment: Developing Motivated Workforce, WHO, Department of Human Resources for Health, Geneva, Switzerland, 12-1

\section{Acknowledgement}

We further extend our sincere gratitude to Professor Frank Carew, University of Maiduguri, Nigeria, Dr (Mrs.) Opaleye, Adebimpe. Prof. H. Morgan and Professor Sahr Gevao for their encouragement and support in making this study possible. We appreciate the support given by the staff of the Ministry of Health and Sanitation, the Registrar Nurses Board, Republic of Sierra Leone and Mr. Sarr James for their vital contributions to the study. This study would not have been possible without the participation of both respondents and staff of the various hospitals. We commend their efforts and cooperation given throughout the study period. 
Table 1: Number of Registered Nurses graduated from 1998-2006

\begin{tabular}{|l|c|c|}
\hline Year & No of Registered Nurses Graduated & No of RNs employed by Government from 1998-2006 \\
\hline 1998 & 17 & NA \\
\hline 1999 & 62 & NA \\
\hline 2000 & 56 & NA \\
\hline 2001 & 54 & NA \\
\hline 2002 & 43 & NA \\
\hline 2003 & 49 & NA \\
\hline 2004 & 35 & NA \\
\hline 2005 & 22 & NA \\
\hline 2006 & 26 & NA \\
\hline Total & $\mathbf{3 6 4}$ & NA \\
\hline
\end{tabular}

Data source: Office of the Registrar for Nurses

Key: NA = Not Available

Table 2: Distribution of Respondents Based on the turnover of RNs

Current employer

\begin{tabular}{|l|l|c|c|c|}
\hline $\begin{array}{l}\text { First employer after } \\
\text { training }\end{array}$ & Frequency & percentage & Frequency & Percentage \\
\hline Government & 202 & & 103 & 97 \\
\hline $\begin{array}{l}\text { Non Governmental } \\
\text { Organization }\end{array}$ & 1 & 0.4 & 08 & 6 \\
\hline Mission/Private & 3 & 1.6 & 25 & 28 \\
\hline Grand Total & 206 & 98 & 133() & 200 \\
\hline
\end{tabular}

Sources; Public and Private Health Institutions

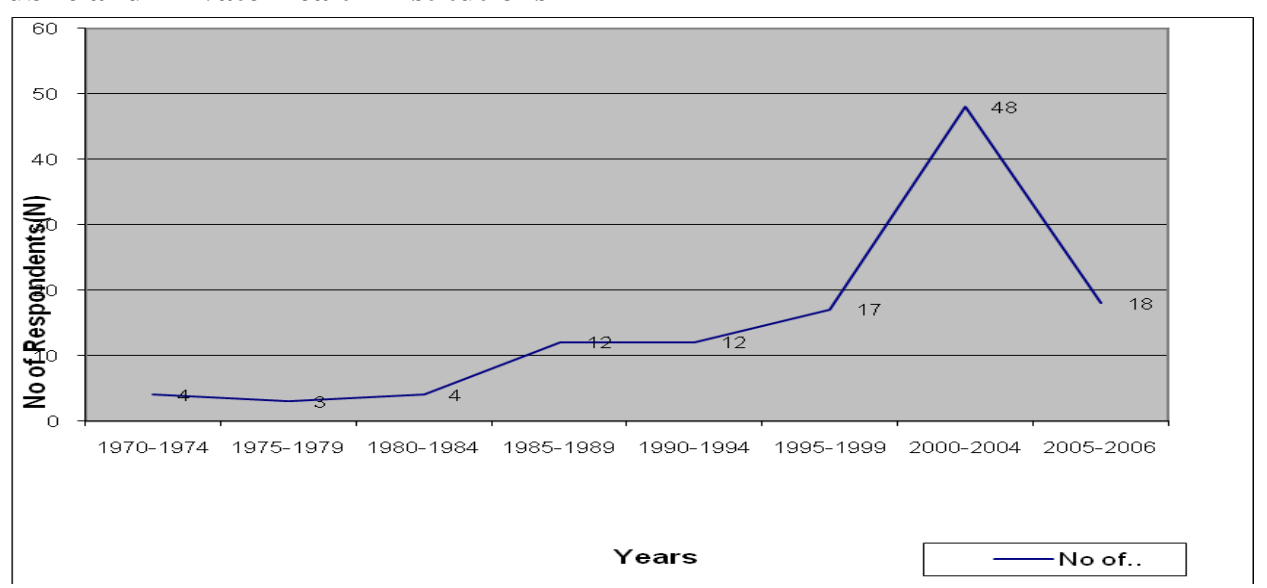

Figure 1:The Training of Registered Nurses

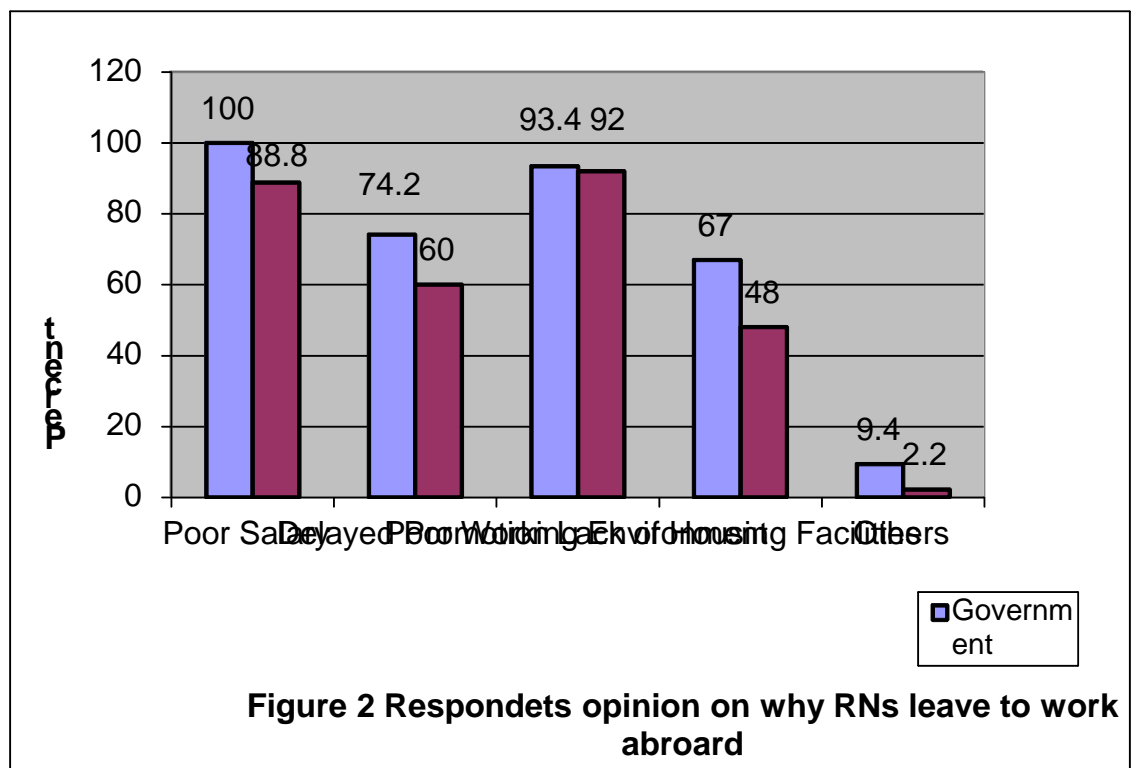




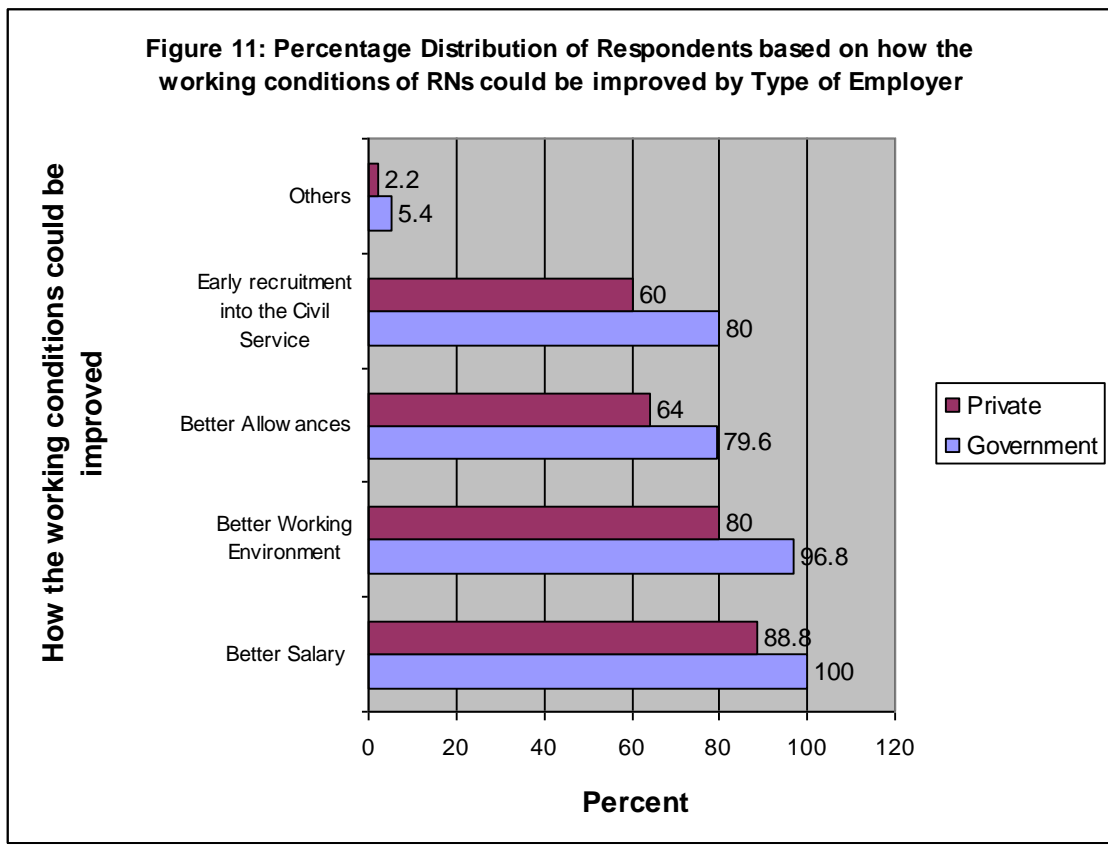

Figure 3: Percentage Distribution of Respondents on how working condition could be improved. 